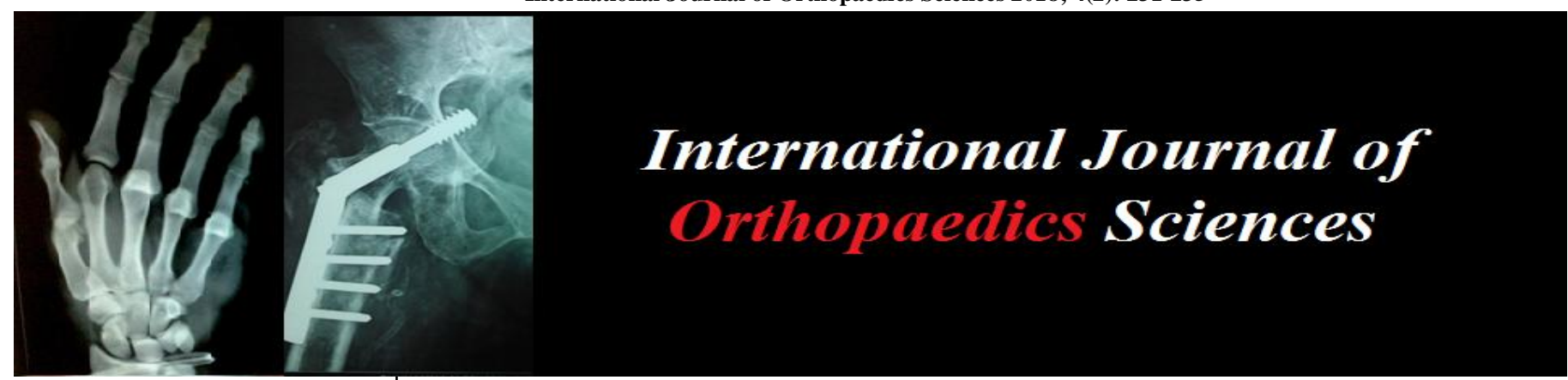

ISSN: $2395-1958$

IJOS 2018; 4(2): 231-235

(C) 2018 IJOS

www.orthopaper.com

Received: 08-02-2018

Accepted: 11-03-2018

Dr. Hemeshwar Harshwardhan J. L. N Medical College and Hospital, Ajmer, Rajasthan, India

Dr. Arun Kumar Rajpurohit J. L. N Medical College and Hospital, Ajmer, Rajasthan, India

Correspondence

Dr. Hemeshwar Harshwardhan

J. L. N Medical College and

Hospital, Ajmer, Rajasthan,

India

\section{Results of distal femur locking plate in communited distal femur fractures}

\section{Dr. Hemeshwar Harshwardhan and Dr. Arun Kumar Rajpurohit}

DOI: https://doi.org/10.22271/ortho.2018.v4.i2d.35

\section{Abstract}

Introduction: A fracture of the distal femur is a grave injury that for years represented an unsolved problem in trauma and was considered to result almost always in varying degrees of permanent disability. Incidence is bimodal with one peak in adolescent boys and men from 15 to 24 [high energy trauma] and second peak in elderly women 75yrs[low energy trauma].In the past closed procedures consisting primarily of traction and splinting had drawbacks like knee stiffness and prolonged immobilisation. Recent advances led to development of Locking Compression Plate (LCP) which is a single beam construct. Further when applied via Minimal Invasive Technique it lowers rate of infection and favours biological fixation.

Materials and Methods: Prospective study of 30 patients with minimum 6 months follow up were included. Communited fractures of distal femur were included in the study

- Implants Used: Plates-The Distal Femur LCP.

- Classification used: AO Classification.

- Clinical and functional outcomes were assessed using Rasmussen's Functional Knee Score.

- Major Complications: like flexion deformity, non union, malunion were assessed.

Results and Observations: 18 patient had excellent result, 10 patient had good result, 1 patient had fair result \& 1 patient had poor result. According to rassamussen's knee score $67.67 \%$ patients had no pain at rest and others had mild to moderate pain at rest. The average time for union was 16.56 weeks with 1 delayed union and no nonunion no malunion. The range of motion in affected knee was 120 degrees in $40 \%$. Upto 90 degrees knee flexion in 24 out of 30 patients. Superficial infection was found in 4 patients. Angulation and plate bending was found in 1 patient due to early full weight bearing.

Conclusion: Thus we can safely recommend the distal femur locking compression plate as a very useful implant in osteoporotic fractures.

Keywords: Results of distal femur locking, femur fractures

\section{Introduction}

A fracture of the distal femur is a grave injury that for years represented an unsolved problem in trauma and was considered to result almost always in varying degrees of permanent disability

Incidence is bimodal with one peak in adolescent boys and men from 15 to 24 [high energy trauma] and second peak in elderly women $75 y$ rs [low energy trauma]. Distal femur fractures have been reported to account for "between" $4 \%$ to $7 \%$ of all femoral fractures

Fractures in supracondylar area characteristically deform with femoral shortening and posterior angulation and displacement of distal fragment.

In the past closed procedures were almost always used in treatment, consisting primarily of traction and splinting.

Major drawbacks like knee stiffness and prolonged immobilisation lead a way towards operative fixation like the blade plate, Dynamic Condylar Screw (DCS). Recent advances led to development of Locking Compression Plate (LCP) which is a single beam construct. Further when applied via Minimal Invasive Technique it lowers rate of infection and favours biological fixation. 


\section{Materials and Methods}

A prospective study of 30 patients was done during a period of January 2016 to January 2018 was done in department of orthopaedics J.L.N MEDICAL COLLEGE AJMER, rajasthan When the patients were seen for the first time after injury, a thorough history was taken regarding time of injury, mechanism, first aid received and significant past. Patients were assessed as per the ATLS guidelines and resuscitated whenever required the clinical diagnosis was confirmed by routine anteroposterior and lateral radiographs of femur with knee. X-rays were assessed for comminution, involvement of joint, displacement and extension of fracture to the shaft. The fractures were classified according to the AO OTA classification system and type A \& C communited fractures were considered in this study.

The condyles were temporarily held reduced and fixed with $\mathrm{K}$-wires in severely displaced intercondylar fractures. All wounds with type II (Gustilo-Anderson) fractures were closed either primarily or secondarily over a drain. Patients were given a course of antibiotics having gram positive, gram negative and anaerobic coverage. The standard lateral approach was used in most of the closed fractures.

Classification: AO classifiation was used in this study

\section{Inclusion Criteria}

1. Closed displaced fractures

2. Open fractures Gustilo Anderson type 1,2 and 3A distal femur fractures

3. 16 or more years of age, regardless of gender

4. Duration of injury $<7$ days.

\section{Exclusion Criteria}

1. Pathological fractures

2. Open fractures type 3B, 3C

3. Any other comorbid illness

4. Age less than 16 years

\section{Implants Used}

1. Plates-The DISTAL FEMUR LCP based on the lcp system

2. Screws-5.0 mm locking screws $1.0 \mathrm{~mm}$ self-tapping locking screws, $5.0 \mathrm{~mm}$ cannulated locking screws, 4.0 $\mathrm{mm}$ locking screws, $4.5 \mathrm{~mm}$ cortical screws, $4.5 \mathrm{~mm}$ cannulated screws.

Surgical Technique: patients were given preoperative antibiotics 30 minutes prior to the operation. All patients were given spinal/epidural proper anaesthesia.

Patient was laid supine on the $\mathrm{O}$. T table, a tourniquet was aaplied to fractured limb. Sterile draping was done and tourniquet inflated.

Approach: lateral par patellar approach was used, Swashbuckler approach was used for better visualisation of condyles in severe communition of condyles and intraarticular involvement.

Clinical and functional outcomes were assessed using Rasmussen's Functional Knee Score

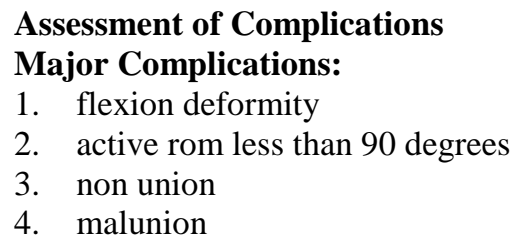

5. deep infection

\section{Minor Complications}

1. slight malunion wiyh no functional problems

2. delayed union

3. plate loosening or breakage that did not required removal

4. superficial infection

\section{Follow up}

The follow up of minimum 6 months was done for all patients. They were examined for condition of operative sites, deformity, tenderness and range of movements. Follow up Xrays were taken to assess any failure of reduction, failure of fixation and fracture union.

Post-operative protocol: Knee brace was given and were started with range of movement exercises as tolerated. A temporary Above Knee slab followed by long leg cast for 4 weeks was given for patients having extensive comminution where stability of fixation was under doubt. Active quadriceps and hamstrings exercises also begun with mobilization. Static quadriceps exercises were instructed whenever the limb was in plaster. Graded weight bearing was allowed depending on $\mathrm{X}$-ray and clinical assessments.

\section{Results}

Overall 30 patients were included in study population. The age ranged from 16 to 78 years. The mean age was 44.16 yrs. The maximum incidence was in 2 peaks one $16-29 \mathrm{yrs}$ and other at $>60 \mathrm{ys}$. Out of 30 patients, $21(70 \%)$ were men and $9(30 \%)$ were women. Road traffic accident was the most common mechanism of injury with $22(73.33 \%)$ patients and trivial trauma was found in $8(26.67 \%)$ patients.

There were 13(43.33\%) type $\mathrm{A}$ and $17(57.66 \%)$ type $\mathrm{C}$ fractures. The sub division showed A2-7, A3-6, C2-12 and C3-5 fractures.

Of the 30 patients, $20(66.66 \%)$ were closed and10 (33.33\%) were open. Of the $3010(30 \%)$ patients had associated bony injuries.

The duration between day of injury and day of fixation in open fractures ranged from 3 to 7 days. 16 patients were operated within 3 days and rest 14 patients were operated within 7 days.

Of the 3027(90\%) were fixed with standard lateral approach, $3(10 \%)$ by antero- lateral. Bone grafting was done for 2 fractures, of which iliac crest cancellous grafting alone was done.

The average time for union was 16.56 weeks, S. D 2.07918 . Radiological union in $<16$ weeks was seen in $9(30 \%)$ patients, in $16-18$ weeks in $18(60 \%)$ patients, $19-20$ weeks in $2(6.67 \%)$ patients and delayed union in 1(3.33\%) patient. No non-union was seen.

The results of entire study group showed 18 excellent, 10 good, 1fair and 1 poor. There was one implant failure (Bending of implant) which occurred following early postoperative weight bearing.

The results AO type a fractures had 10 excellent and 3 good. The results of AO type $\mathrm{C}$ fractures had 8 excellent, 7 good, 1 fair and 1 poor results. Results of open fractures showed 3 excellent, 5 good, 1 fair and 1 poor results. Results of closed fractures showed 15 excellent and 5 good. We saw that 3 of $10(33.33 \%)$ open fractures had excellent results whereas 15 out of 20(75\%) closed fractures had excellent results.

The 13 of 13 type a fractures had excellent or good results whereas 15 of 17(40\%) type $\mathrm{C}$ fractures had excellent or good 
results.

The closed fractures united early as compared to open fractures. Of 30 patients that were included in the study $18(63.33 \%)$ had range of motion greater than 120 degrees. The type a fractures had a better range of movement as compared to type $\mathrm{C}$ fractures.

\section{Discussion}

Supracondylar-intercondylar fracture of femur, historically have been difficult to treat. These fractures often are unstable and comminuted and have a potential

For long term disability. The literature review shows various different implants and techniques in the management of these fractures, the use of these devices requires a certain amount of bone stock present, which limits their use in some fracture types. The standard buttress plate, even though, can be used in comminuted fractures, often ends with varus deformity.7-9 Biomechanical studies revealed gross loosening because of toggle at screw-plate interface. Advance in mechanization and acceleration of travel have resulted in increased incidence of such comminuted, unstable fractures. Increasing geriatric population and osteoporosis has added to the problem.10-12 Figure 1, 2, 3, 4, 5: AP and Lateral views of pre and postoperative fracture fixation

Figure 6, 7: Range of movement after union.

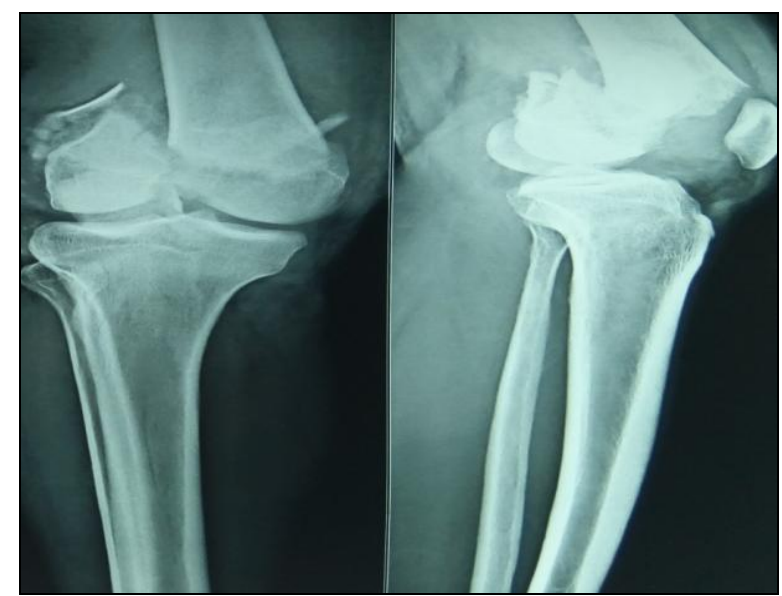

Fig 1: preoperative

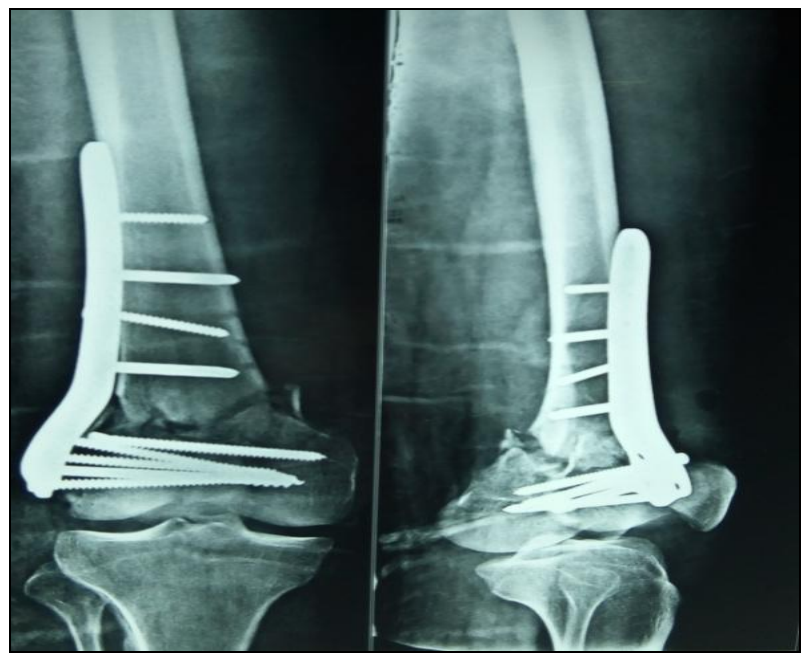

Fig 2: Immediate Postoperative

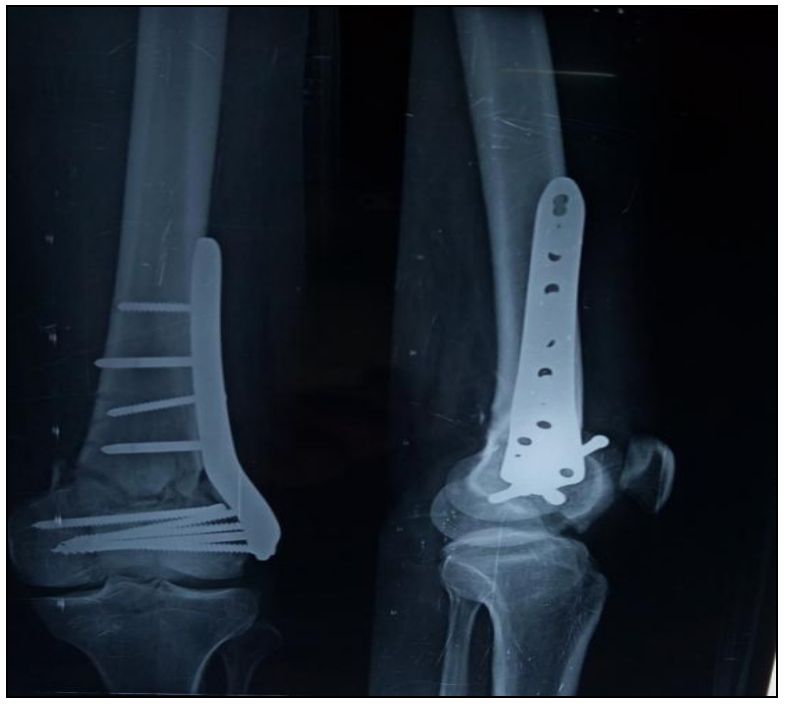

Fig 3: 1 Month Postop

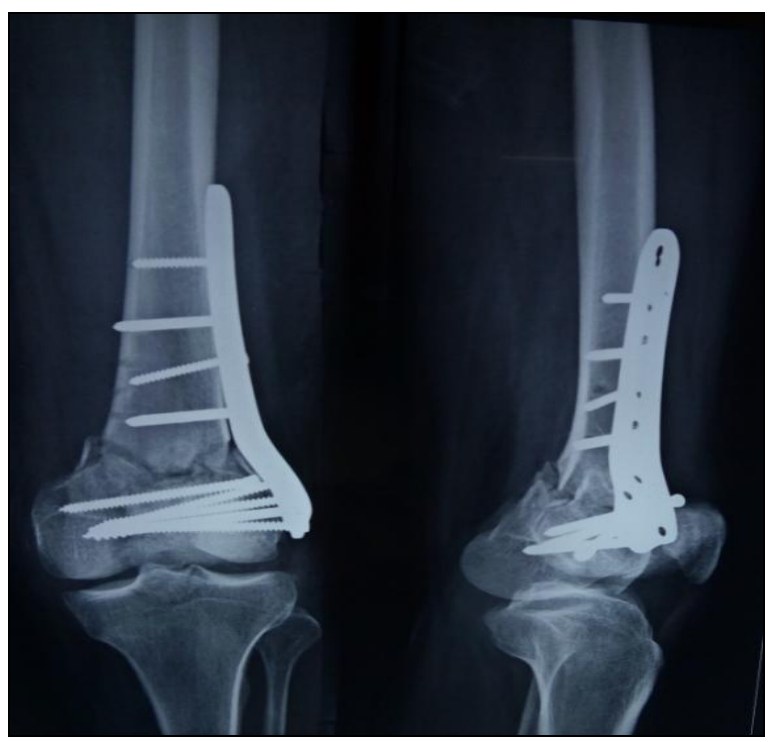

Fig 4: 2.5 Months Postop

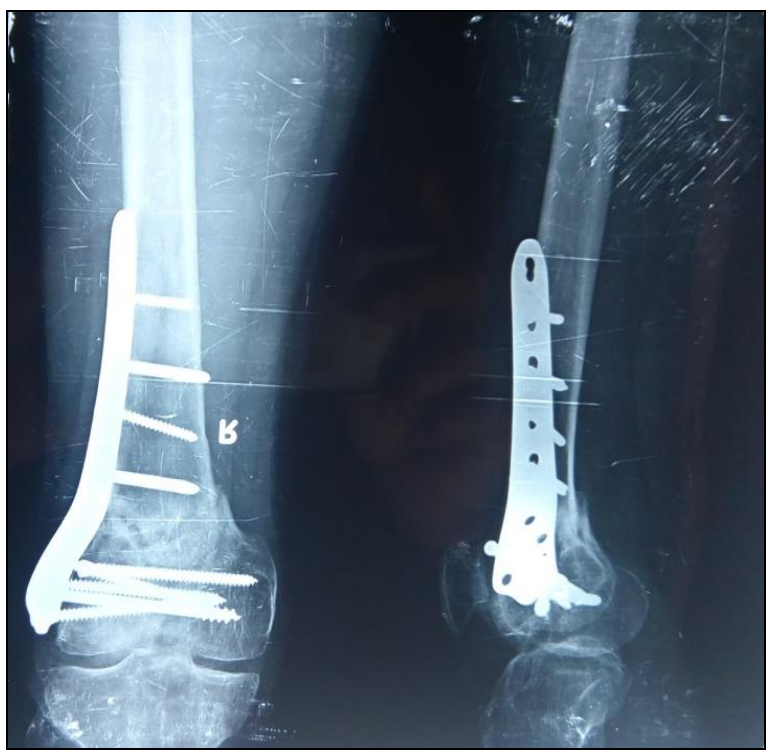

Fig 5: 6 Months Postop 


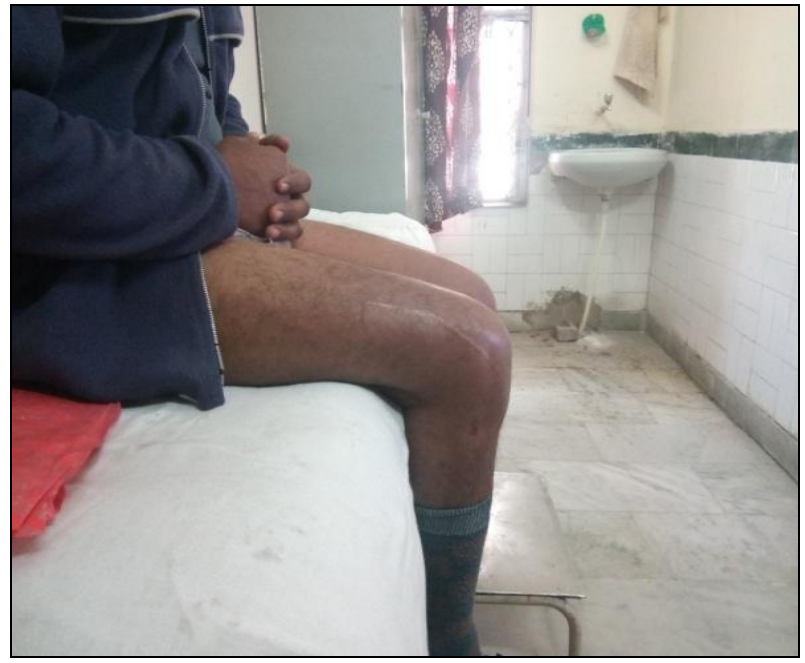

Fig 6: Full 90 Degree Knee Flexion

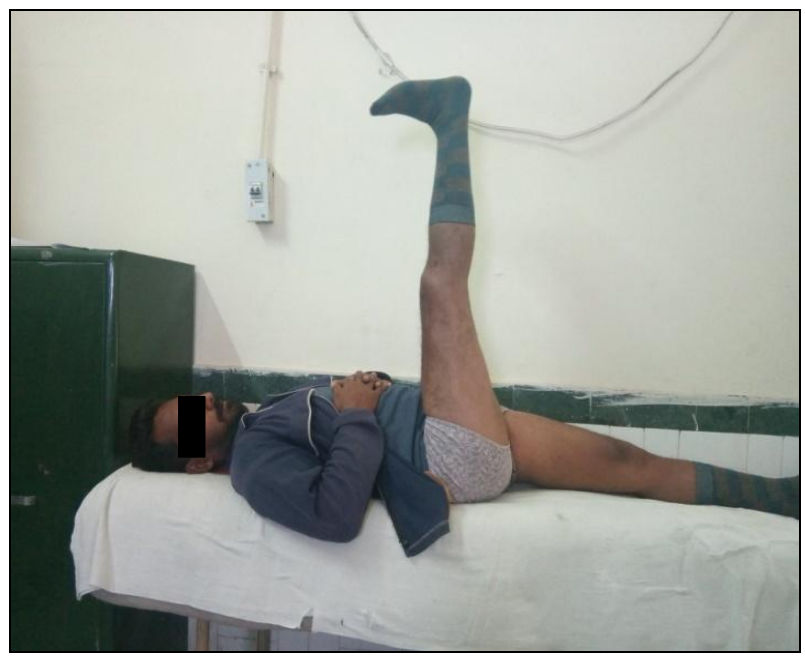

Fig 7: Full Knee Extension

The LCP is a single beam (fixed angle) construct where strength of its fixation is equal to the sum of all screw- bone interfaces rather than a single screw's axial stiffness and pull out resistance as in unlocked plates. It acts as an internal fixator' and functions by splinting the fracture rather than compression and hence allows a flexible stabilization, avoidance of stress shielding and induction of callus formation. Figure 3, 4

In this study the outcome of such comminuted fractures which were fixed using distal femoral LCP has been assessed. Attempt is made to find out the effect of different associated variables (like open or closed, intra or extra articular) on the outcome. The rates of union and complications are also analysed.

The present study of 30cases indicates road traffic accidents as predominant cause of fractures $(73.33 \%)$ and other causes being fall from height and trivial fall on flexed knee. Majority of patients were males $(70 \%)$ in their active age. this reflects that young and active individuals are prone to this fracture due to high velocity injuries. There was biphasic age distribution as seen in other studies (Bell et al., 1992).13 the average age was less (44.16yrs) as compared to other reported series: Healy et al., 48 yrs. 14

Eleven of the patients had associated injuries, which included 10 major fractures thus proving that these fractures are components of poly trauma. Ten of thirty (30\%) fractures were open. The incidence was high as compared to that published in literature i. e. 5-10\%. This could be because most of the fractures included in the series were following high velocity road traffic accidents and the study group was small.

Muller's comprehensive classification system was used to classify the fractures. There were 13/30(43.33\%) type A and $17 / 30(66.66 \%)$ type $C$ fractures. It was also observed that 8 of 17 type $\mathrm{C}$ fractures had associated injuries, again attributing the increased incidence of type $\mathrm{C}$ injuries to high velocity injuries.

The average duration from the date of injury to date of surgery was 4.2 days. The mean time for union was 16.56weeks.

One of the most common complications of distal femoral fractures is knee stiffness. The average post-operative active range of motion as reported by Seinsheimer et al. was 91 degrees. 15 the average range of motion in our series is 60 to 125 degrees. Another dreaded complication is infection, Neer et al. has reported $20 \%$ infection rate. 16 Others like M Silisky et al. reported $5.7 \%$ infection. $17 \mathrm{We}$ had $1 / 30(3.33 \%)$ infection which was superficial and got settled after a course of antibiotics and wound wash out.

There was one case of implant failure, where the implant got bent following an early post-operative weight bearing. The patient was advised resurgery and refixation was done. There were no malunions. There was one delayed union (33 weeks) which required a second surgery for bone grafting. Kiran et al. reported 2 cases of non-union.

RASSAMUSSEN functional knee score system was used for functional evaluation. There were 18 excellent, 10 good, 1 fair and 1 poor results. Comparison of present study with the study by Yeap et al. and the one by Wesley PP et al. total 11 patients, with 4 excellent, 4 good, 2 fair and one failure.

\section{Conclusion}

The outcome of closed fractures was found better than open fractures. The extra articular (type A) fractures had better outcome than intra articular (type C) fractures. The closed fractures united earlier as compared to open fractures. There was no significant difference in time of union in fractures where bone graft was used and in those where no bone graft was used. Knee stiffness is a common complication following these fractures. The rate of union is comparable to similar series whereas the average duration for union is high. There were no cases with secondary loss of reduction, loss of fixation or non-union.

Therefore the distal femoral LCP provides a stable fixation in comminuted fractures. In the study, many groups taken for comparison were very small (type of open fractures, individual AO types). It needs a wider study involving more number of cases in each group and a larger follow up to fully defined the place of distal femoral LCP alongside the existing technology in fractures of distal femur.

\section{Acknowledgements}

We thank all the technical staff and nurses who helped us in performing the surgeries and this study.

\section{References}

1. Kiran kumar GN, Sharma G, Farooque K, Sharma V. Locking compression plate in distal femoral intra articular fractures: our experience. International scholarly research, 2014.

Article in 372916.

2. Hoffmann MF, Jones CB, Sietsema DL. Clinical outcomes of locked plating of distal femoral fractures in a retrospective cohort. Journal of orthopedic surgery and 
research. 2013; 8:43.

3. Yeap EJ, Deepak AS. Distal Femoral Locking Compression Plate Fixation in Distal.

4. Femoral Fractures. Early Results Malaysian Orthopaedic Journal. Parker DA, Lautenschlager EP, Caravelli ML, Flanigan DC, Merk BR. A Biomechanical Comparison of Distal Femoral Fracture Fixation: The Dynamic Condylar Screw, Distal Femoral Nail, Locking Condylar Plate, and Less Invasive Stabilization System. OTA. 2005, 2007; 1(1):5.

5. Krettek C, Muller M, Miclau T. Evolution of Minimally Invasive Plate Osteosynthesis (MIPO) in the femur. Injury. 2001; 3:14-23.

6. Krettek C, Schandelmaier P, Miclau T. Minimally invasive percutaneous plate osteosynthesis (MIPPO) using the DCS in proximal and distal femoral fractures. Injury. 1997; 28:20-30.

7. Kubiak EN, Fulkerson E, Strauss E, Egol KA. Evolution of Locked Plates. The Journal of Bone and Joint Surgery. 2006; 88:189-200.

8. Giles JB, Delee JC, Heckman JD. Supracondylarintercondylar fractures of the femur treated with a supracondylar plate and lag screw. J Bone Joint Surg Am. 1982; 64:864-70.

9. Brown A, D'Arcy JC. Internal fixation for supracondylar fractures of the femur in the elderly patient. J Bone Joint Surg Br. 1971; 53420-4.

10. Ahmad M, Nanda R, Bajwa AS, Candal-Couto J, Green $\mathrm{S}$, Hui AC. Biomechanical testing of the locking compression plate: when does the distance between bone and implant significantly reduce construct stability? Injury. 2007; 38(3):358-64.

11. Parker DA, Lautenschlager EP, Caravelli ML, Flanigan DC, Merk BR. A Biomechanical Comparison of Distal Femoral Fracture Fixation: The Dynamic Condylar Screw, Distal Femoral Nail, Locking Condylar Plate, and Less Invasive Stabilization System. OTA, 2005.

12. Egol KA, Kubiak EN, Fulkerson E, Kummer FJ, Koval KJ. Biomechanics of locked plates and screws. J Orthop Trauma. 2004; 18(8):488-93.

13. Bell KM, Johnstone AJ, Court Brown CM, Hughes SP. J Bone Joint surg Br. 1992; 74:400-02.

14. Healy WL, Siliski JM, Incavo SJ. Operative treatment of distal femoral fractures proximal to total knee replacements. J Bone Joint Surg Am. 1993; 75:27-34.

15. Seinsheimer F. Fractures of the distal femur. Clin Orthop Relat Res. 1980; 153:169-79.

16. Neer CS, Grantham SA, Shelton ML. Supracondylar fracture of the adult femur. J Bone Joint Surg Am. 1967; 49:591-613.

17. Siliski JM, Mahring M, Hofer HP. SupracondylarIntercondylar fractures of femur. JBJS. 1989; 71A:95104.

18. Phipatanakul WP, Mayo KA, Mast JW, Bolhofner BR. Reconstruction of the Distal Femur with Use of a New Device: The Locking Condylar Plate. OTA. 2001. 20. Phipatanakul WP, Mayo KA, Mast JW. Treatment of Distal Femur Fractures with New Device; the Locking Condylar Plate. OTA, 2005. 